\title{
Patients Perspective on Multiple vs. Single-occupancy Rooms in a Busy District Hospital
}

\author{
Tariq S, Chauhan $\mathrm{MN}^{*}$, Ahmed SE and Canelo R
}

Cumberland Infirmary Surgery, Newtown Rd, Carlisle United Kingdom, CA2 7HY, United Kingdom

\begin{abstract}
Objective: The benefits of single occupancy vs. multiple occupancy rooms have been extensively debated over in the last few decades. The aim of this prospective study was to evaluate patient experience and preferences for room occupancy within the context of privacy, confidentiality, care, comfort and service satisfaction.

Methodology: A survey questionnaire comprising of 15 questions (see Pro forma) broadly covering the elements of privacy, comfort, and satisfaction was randomly distributed on the surgical floor of Cumberland infirmary Carlisle UK in April 2016. A total of 119 patients participated in the study.

Results: It was noted that $15 \%$ of the subjects in multiple occupancy ward believed that their expectations of confidentiality were not being met compared to $6 \%$ of subjects in single occupancy room. Patients in single occupancy rooms reported less sleep disturbance at night and lower ambient noise and less crowding. With regards to comfort and care, $84 \%$ of patients in single occupancy were very satisfied with the overall service vs. $78 \%$ of patients in multiple occupancy rooms. We found that staff response to patient needs was also better managed in the single-occupancy room compared to the multi-occupancy bay. On the other hand, the occupants of the single rooms reported feeling more isolated, exhausted and neglected. Regarding room preference, a majority of patients in each group preferred to retain occupancy. However, a significant proportion from multiple occupancy bay preferred single occupancy room.

Conclusion: The Major drawbacks of multiple occupancy rooms were privacy, confidentiality, and comfort. The multiple occupancy bay were a breach when keeping in with the information governance guidelines. On the other hand, patients in a single occupancy room felt more isolated, exhausted and neglected. In each group, the majority maintained their preference but when compared to multiple occupancy bay a larger percentage of patients in single occupancy rooms were satisfied with their experience.
\end{abstract}

Keywords: single occupancy vs. multiple occupancy; Patients; Hospital; survey

\section{Introduction}

The difference between single-occupancy and multiple-occupancy rooms has been the topic of numerous publications with ambiguous results regarding patients' preference. The difference of opinion between the care givers and receivers are also well documented. Most extensively discussed are the advantages and disadvantages in regard to infection control and cost-effectiveness. Single occupancy rooms are steadily becoming more popular both nationally and internationally, despite the fact that multiple occupancy are more cost effective. In this study, we aim to assess the experience of the patients at the receiving end of the care in the context of their comfort, service satisfaction confidentiality and privacy.

\section{Methods}

The prospective study was conducted at Cumberland Infirmary Carlisle UK in April 2016 over a period of four weeks. The subject pool included patients on the surgical floor with the exception of critically ill. A survey questionnaire consisting of 15 questions (See Pro forma) broadly covering privacy, confidentiality, patient comfort, service satisfaction and personal preference was distributed. The patients were asked to rate the care they were provided and the response of the staff to patient needs. Also taken into consideration were factors like ambient and outside noise, crowding, sleep disturbance, exhaustion, and isolation. In the end, the patients were asked if they would prefer to be in a single room or a multi-occupancy room. Analysis of the study was carried out using Microsoft Excel and
MedCalc ${ }^{\circ}$. Chi square test was performed to calculate the statistical significance between the percentages in the groups a $\mathrm{p}$ value of $<0.05$ was considered to be significant.

\section{Results}

A total of 119 patients participated in the survey, of which 52 (44\%) patients were residing in single-occupancy rooms and 67 (56\%) patients in the multi-occupancy rooms. The average age of the study population was 57 years and the male-to-female ratio was 1:1.8.

\section{Privacy and confidentiality}

Our study shows that $55 \%$ of the patients in multiple-occupancy rooms were able to overhear other patient's sensitive medical information comparing to $17 \%$ in single-occupancy $\mathrm{p}<0.0001(95 \%$ CI 20.8 -51.7). Another 52\% of multiple-occupancy residents also believed that their medical information was over-heard by others $v s$.

*Corresponding author: Chauhan MN, Cumberland Infirmary Surgery, Newtown Rd, Carlisle United Kingdom, CA2 7HY, United Kingdom, Tel: +00447795109561; E-mail: specialistsurgeon@yahoo.co.uk

Received August 28, 2018; Accepted September 29, 2018; Published October 06, 2018

Citation: Tariq S, Chauhan MN, Ahmed SE, Canelo R (2018) Patients Perspective on Multiple vs. Single-occupancy Rooms in a Busy District Hospital. J Pat Care 4 142. doi: $10.4172 / 2573-4598.1000142$

Copyright: ( 2018 Tariq S, et al. This is an open-access article distributed under the terms of the Creative Commons Attribution License, which permits unrestricted use, distribution, and reproduction in any medium, provided the original author and source are credited. 
$17 \%$ in single-occupancy $\mathrm{p}=0.0001$ ( $95 \%$ CI $17.9-48.9$ ). Only $9 \%$ of the patients in the multiple-occupancy bay admitted to withholding information due to fear of being overheard and $8 \%$ of the occupants of single-occupancy room admitted to doing the same ( $\mathrm{p}=0.84)$. A total of $13 \%$ of patients in multiple-occupancy bay and $4 \%$ of subjects in single-occupancy room answered yes to seeing other patients exposed $(\mathrm{p}=0.09)$. It was also noted that $12 \%$ of patients in multipleoccupancy ward believed they were seen by other patients when they were not properly dressed and $6 \%$ of patients in single-occupancy rooms felt the same $(\mathrm{p}=0.26)$. Another $15 \%$ of patients residing in multiple-occupancy rooms did not believe that their expectations of confidentiality were being met, whereas the percentage of patients in single-occupancy room, who felt the same, was only $6 \%(\mathrm{p}=0.12)$. The different parameters of privacy and confidentiality are compared in the Graph 1 below.

\section{Patient comfort}

To assess patient comfort, questions regarding overcrowding, noisiness, sleep disturbance and exhaustion were asked in the survey. A total of $45 \%$ of patients in multiple-occupancy wards reported overcrowding vs. $12 \%$ in single-occupancy rooms and $58 \%$ of patients in multiple-occupancy wards indicated that it was noisy compared to $29 \%$ in single-occupancy. In both of these parameters there was statistically significant association with multiple occupancy bay/ward (Table 1).

It was noted that $37 \%$ of patients residing in single-occupancy rooms experienced sleep disturbance in contrast to $52 \%$ in multipleoccupancy rooms. Whereas $47 \%$ in single-occupancy felt exhausted in comparison to $37 \%$ in multiple-occupancy ward.

\section{Service satisfaction}

The response to the bell was found to be poor and statistically significant in multiple-occupancy wards as $33 \%$ felt that the staff response was poor in contrast only $12 \%$ in single-occupancy felt the same (Table 2). It was found that patients in single-occupancy rooms felt more isolated and neglected, $16 \%$ and $21 \%$ respectively. Whereas in comparison only $8 \%$ in multiple-occupancy rooms felt isolated and $11 \%$ felt neglected. Finally, overall satisfaction remained at $84 \% v s .78 \%$ when compared between single occupancy and multiple occupancy groups.

\section{Patient preference}

At the end of the survey, the subjects were asked about their preference, the majority of each group maintained their preference. $50 \%$ of patients in multiple-occupancy rooms preferred to stay in multiple-occupancy ward and $63 \%$ of patients in single-occupancy preferred single-occupancy (Table 3 ). The graph below shows the comparison of preference.

\section{Discussion}

While the issue of single-occupancy $v s$. multiple-occupancy within hospital and care facilities is well-documented, most of the current literature focuses on the aspects of infection control, healthcare facility management and cost-effectiveness [1,2]. Our study aims to add a new dimension by discussing patient experience and preference.

Previous research literature shows that single-occupancy rooms are effective in preventing cross infection [1,2]. In a study, there was observed lower HAI (hospital acquired influenza) risk among patients hospitalized in single-occupancy rooms than those in doubleoccupancy rooms [2]. In regards to cost-effectiveness and facility management, Thompson and Goldin (1975) argued that multipleoccupancy bay are the most economically efficient. In their study, the staff reported that the placement of patient beds along one corridor provided a direct line of sight for nursing staff, aiding the supervision and reducing travel time for nurses $[3,4]$, this also reduced the costs

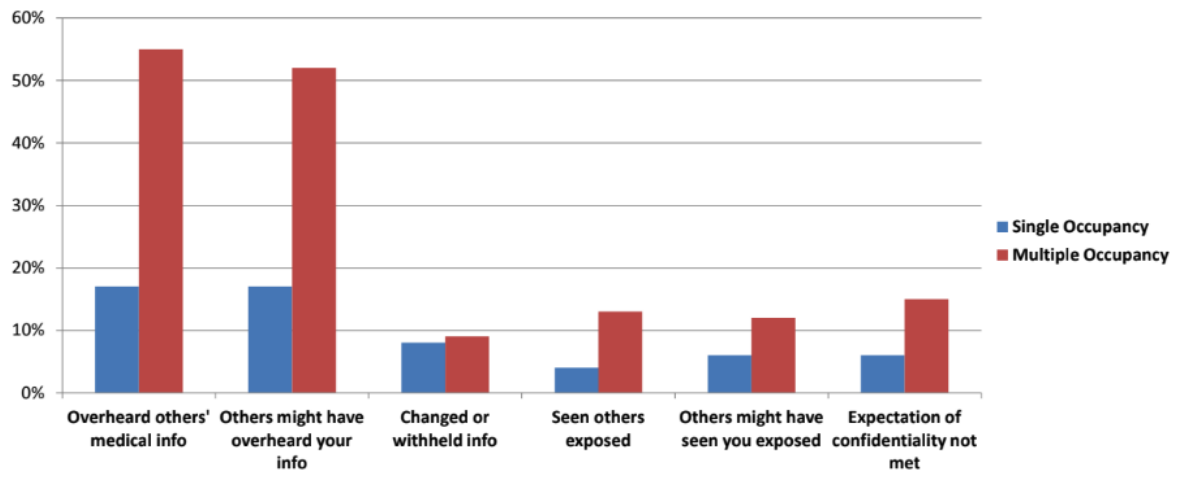

Graph 1: The different parameters of privacy and confidentiality are compared in the graph.

\begin{tabular}{|c|c|c|c|}
\hline \multicolumn{4}{|c|}{ PATIENT COMFORT } \\
\hline & $\begin{array}{c}\text { Single } \\
\text { Occupancy } \\
(\mathbf{n = 5 2 )}\end{array}$ & $\begin{array}{c}\text { Multiple } \\
\text { Occupancy } \\
(\mathbf{n = 6 7 )}\end{array}$ & p Value \\
\hline Over Crowding & $12 \%$ & $45 \%$ & $\mathrm{p}=0.0001(95 \% \mathrm{Cl} 16.8-46.4)$ \\
\hline Noise & $29 \%$ & $58 \%$ & $\mathrm{p}=0.0017(95 \% \mathrm{Cl} 11-44.2)$ \\
\hline Sleep Disturbance & $37 \%$ & $52 \%$ & $\mathrm{p}=0.10$ \\
\hline Felt Exhausted & $47 \%$ & $37 \%$ & $\mathrm{p}=0.27$ \\
\hline
\end{tabular}

Table 1: Patient comfort.

\begin{tabular}{|c|c|c|c|}
\hline \multicolumn{4}{|c|}{ SERVICE SATISFACTION } \\
\hline & $\begin{array}{c}\text { Single } \\
\text { occupancy } \\
(n=52)\end{array}$ & $\begin{array}{l}\text { Multiple- } \\
\text { occupancy } \\
(n=67)\end{array}$ & p Value \\
\hline Felt isolated & $16 \%$ & $8 \%$ & $p=0.1766$ \\
\hline Poor response to bell & $12 \%$ & $33 \%$ & $\begin{array}{c}\mathrm{p}=0.0079(95 \% \text { Cl 5.6- } \\
34.4)\end{array}$ \\
\hline Felt neglected & $21 \%$ & $11 \%$ & $p=0.13$ \\
\hline Overall satisfaction & $84 \%$ & $78 \%$ & $p=0.41$ \\
\hline
\end{tabular}

Table 2: Service satisfaction. 
Citation: Tariq S, Chauhan MN, Ahmed SE, Canelo R (2018) Patients Perspective on Multiple vs. Single-occupancy Rooms in a Busy District Hospital. J Pat Care 4: 142. doi: 10.4172/2573-4598.1000142

Page 3 of 4

\begin{tabular}{|c|c|c|c|}
\hline \multicolumn{3}{|c|}{ PATIENT PREFERENCE } \\
\hline $\begin{array}{c}\text { Preferred multiple } \\
\text { occupancy }\end{array}$ & Single occupancy (n=52) & Multiple-occupancy (n=67) & p Value \\
\hline Prefer single occupancy & $16 \%$ & $50 \%$ & $\mathrm{p}=0.0001(95 \% \mathrm{Cl} 17.1-47.8)$ \\
\hline No preference & $63 \%$ & $29 \%$ & $\mathrm{p}=0.0002(95 \% \mathrm{Cl} 16-49.1)$ \\
\hline
\end{tabular}

Table 3: Patient preference.

\begin{tabular}{|l|l|}
\hline Age: & Sex: Male $\quad$ Female \\
\hline Single occupancy room & Multiple occupancy ward \\
\hline
\end{tabular}

1. Can you overhear other patient's personal information?

2. Can other patients hear your personal information?

3. Have you ever changed or withheld information because you fear others might overhear.

4. Are your expectations of confidentiality being met?

5. Have you seen other patients exposed?

6. Have other patients seen you exposed?

\begin{tabular}{|l|l|l|l|}
\hline & Mild (0-3) & Moderate (4-6) & Severe or Best (7-10) \\
\hline 7. Overcrowding & & & \\
\hline 8. Noise level & & & \\
\hline 9. Sleep Disturbance & & & \\
\hline 10. Felt exhausted & & & \\
\hline 11. Felt Neglected & & & \\
\hline 12. Felt isolated & & & \\
\hline 13. Staff response to bell & & Multiple occupancy ward & No Preference \\
\hline 14. Overall Satisfaction & & & \\
\hline 15. Your Preference & & & \\
\hline
\end{tabular}

Table 4: Pro Forma Single occupancy vs. multiple occupancy Survey in Cumberland Infirmary Carlisle UK.

associated travel time [5]. In another study Staff reported that patient comfort and confidentiality was better in $100 \%$ single rooms but felt single rooms were worse when it came to patient monitoring and visibility, teamwork, safeguarding and being close to patients [6]. However, according to our survey, the patients in single rooms were more satisfied with the staff as the response to the patients' call was substantially better than the response observed by the patients in multiple-occupancy rooms.

Our survey concluded that a significant percentage of patients in multiple-occupancy rooms can overhear medical and confidential information, and therefore believe that their information is also heard by other patients. The breach of personal information can have legal consequences. This can also lead to withholding information for the fear of embarrassment. Previous literature have also shown that patients in multi-bay curtained areas compared with those in walled rooms, believed that others could hear them, that they could overhear others, and that others could inappropriately view them. The perceived invasion of privacy led to a small percentage of the patients in the multiple occupancy bay admitting that they withheld personal aspects of their medical history and refused certain parts of their physical examination [7-9]. Complete information by the patient is important for diagnosis; Withholding information may lead to misdiagnosis because doctors are operating with incomplete information.

Patients in multiple-occupancy rooms also feel more exposed to other patients and this may lead to stress and anxiety due to embarrassment [10]. According to Lawson \& Phiri, patients felt unpleasantness and frustration of not being able to control their 
Citation: Tariq S, Chauhan MN, Ahmed SE, Canelo R (2018) Patients Perspective on Multiple vs. Single-occupancy Rooms in a Busy District Hospital. J Pat Care 4: 142. doi: 10.4172/2573-4598.1000142

community and privacy. Our survey shows that multiple-occupancy bays present a total breach of confidentiality not in keeping with the information governance guidelines. A sense of privacy and not being exposed to other patients during examinations may lessen frustration [11], therefore according to our study more patients in singleoccupancy were more satisfied with their care.

The patients of single-occupancy room also reported less noise, no overcrowding, fewer interruptions at night and therefore, a better night's sleep. It has generally been shown that noise roughly causes $11 \%$ to $20 \%$ of arousals and awakenings during sleep [12]. It is established that anxiety disorders are also associated with interrupted sleep [13]; a better nights' sleep and the concurrent lowered anxiety leads to quicker recovery and better satisfaction of the patients. Kirk conducted a study in a hospice in England and he found that a majority of patients preferred room with single occupancy as it offered more privacy, less ambient noise, better quality of sleep, less embarrassment and also because family members could stay without upsetting other patients [13].

Regarding the negative aspects of single-occupancy rooms, several studies [14] have indicated that patients in single-occupancy rooms tend to feel lonely. Our survey also showed that more patients in single-occupancy rooms felt isolated and neglected. Despite that, a large proportion of patients in single-occupancy rooms prefer to retain occupancy and a significant percentage of patients in the multipleoccupancy bay also admitted to preferring single-occupancy rooms. Surveys conducted at the Royal Victoria Hospital in 2008 and 2013 indicate a marked rise in preference for a single room by patients (Table 4). This may be due to introduction of open visiting and care rounding which reduces the risk of isolation in single rooms [15].

\section{Conclusion}

Single-occupancy rooms have multiple advantages like improvement in privacy and confidentiality, improvement in patient care, less disturbance in sleep and reduced anxiety due to noise and embarrassment. The disadvantages are feelings of isolation and neglect. Patients believe the advantages outweigh the disadvantages and therefore more patients in single-occupancy room prefer to retain occupancy and a significant proportion of subjects in multipleoccupancy wards feel the same and overall satisfaction of patients in single-occupancy room is considerably more than the subjects in multiple-occupancy rooms.

\section{References}

1. Chaudhury $\mathrm{H}$, Mahmood A, Valente $\mathrm{M}$ (2005) Advantages and disadvantages of single-versus multiple-occupancy rooms in acute care environments. Environ Behav 37: 760-786.

2. Munier-Marion E, Bénet T, Régis C, Lina B, Morfin F, et al. (2016) Hospitalization in double-occupancy rooms and the risk of hospital-acquired influenza: A prospective cohort study. Clin Microbiol Infect 22: 461.e7-461.e9.

3. Thompson J, Goldin G (1975) The hospital: A social and architectural history. New Haven: Yale Univ Press 20: 457-458.

4. Chaudhury H, Mahmood A, Valente M (2006) Nurses' perception of singleoccupancy versus multioccupancy rooms in acute care environments: An exploratory comparative assessment. Appl Nurs Res 19: 118-125.

5. Maben J, Griffiths P, Penfold C, Simon M, Pizzo E, et al. (2015) Evaluating a major innovation in hospital design: Workforce implications and impact on patient and staff experiences of all single room hospital accommodation. Health Serv Deliv Res 3: 1-304.

6. Ampt A, Harris P, Maxwell M (2008) The health impacts of the design of hospital facilities on patient recovery and wellbeing: A review of the literature. Centre for Primary Healthcare and Equity, University of New South Wales, Sydney.

7. Joseph A, Ulrich R (2007) Sound control for improved outcomes in healthcare settings. The Center for Health Design.

8. Ulrich R, Quan X (2004) The role of the physical environment in the hospita of the $21^{\text {st }}$ century: A once-in-a-lifetime opportunity. Designing the $21^{\text {st }}$ century hospital project, The Center for Health Design.

9. Kirk S (2018) Patient preferences for a single or shared room in a hospice. 5 169-174.

10. Lawson B, Phiri M (2003) The architectural healthcare environment and its effects on patient health outcomes. A Report on an NHS Estates Funded Research Project 3: 1-27.

11. Hsu T, Ryherd E, Persson Waye K, Ackerman (2012) Noise pollution in hospitals - Impact on patients. JCOM 19: 301-309.

12. Aurell J, Elmqvist D (1985) Sleep in the surgical intensive care unit: Continuous polygraphic recording in nine patients receiving postoperative care. $\mathrm{Br}$ Med J 290:1029-1032.

13. Desjardins S, Leblanc M, Desgagné A (2015) Sleep problems in anxious and depressive older adults. Psychol Res Behav Manag 8: 1.

14. Maben J, Griffiths P, Penfold C, Simon M, Pizzo E, et al. (2015) Evaluating a major innovation in hospital design: Workforce implications and impact on patient and staff experiences of all single room hospital accommodation. Health Serv Deliv Res 3: 1-304.

15. Reid J, Wilson K, Anderson K, Maguire C (2014) Older inpatients' room preference: Single versus shared accommodation. Age and Ageing 44: 331-333. 